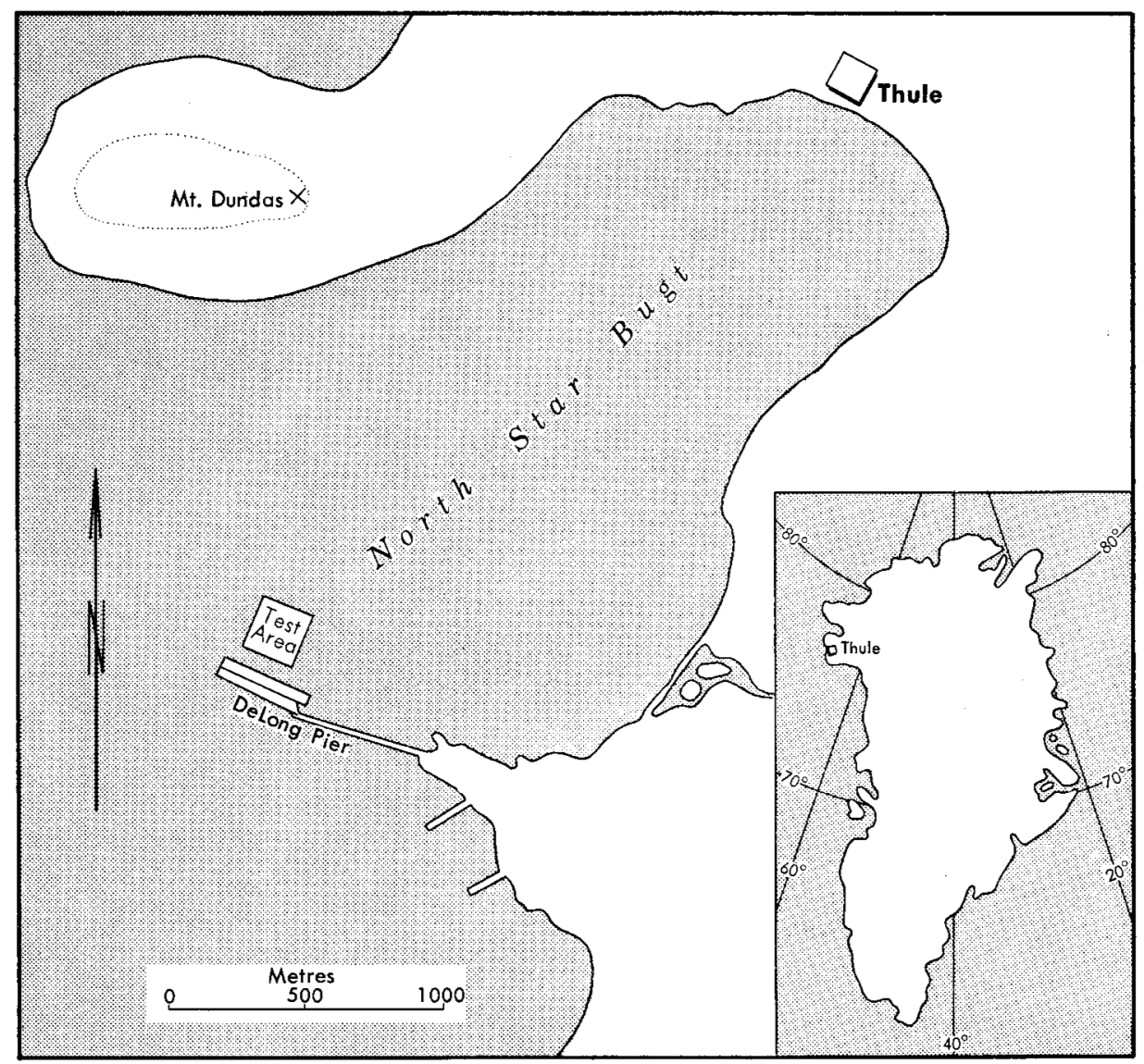

Fig. 1. Map of the North Star Bay area, Thule, Greenland, showing the location of the test site. 


\title{
Papers
}

\section{THE SALINITY DISTRIBUTION IN YOUNG SEA-ICE}

\author{
W. F. Weeks* and O. S. Lee†
}

\section{Introduction}

W HeN attempts have been made to study such properties of sea-ice as strength, density, latent heat of melting, and thermal conductivity, it has been found that a large scatter in values is obtained from tests performed on ice samples of apparently similar histories, temperatures, and salinities (Malmgren 1927; Petrov 1955; Butkovich 1956, 1959; Weeks and Anderson 1958; Weeks and Lee 1958). The major variation of these bulk properties has been ascribed to changes in the brine content of the sea-ice (Anderson and Weeks 1958; Anderson 1958, 1960). If the temperature at any given depth in an ice-sheet of uniform thickness and structure is approximately constant, lateral variations in salinity of the sheet perhaps may account for much of the scatter in bulk-property values found in field studies. For example, after an in-place or small-sample strength test has been performed, it is essentially impossible to determine the salinity of the ruptured surface. Therefore, usually either a salinity sample is cored from "similar" ice in the near vicinity of the test site or the salinity of the whole test sample is determined and assumed to represent the salinity of the ruptured surface. This salinity value is then combined with the temperature of the sample to compute the brine content by volume of the sample at the time of testing. Tables of the brine content by volume of sea-ice vs. ice temperature (Assur 1958 , p. 138) show that, particularly at ice temperatures above $-6^{\circ} \mathrm{C}$., small differences between the measured salinity and the actual salinity of the breaking surface will result in large errors in the assumed brine content by volume and will therefore produce a large scatter in the resulting data. The purpose of this study is to examine the lateral and vertical salinity variation in known types of naturally occurring sea-ice with the hope that a better understanding of the salinity distribution will permit the design of improved sampling procedures and perhaps result in a reduction of the scatter of test results.

*Materials Research Branch, Cold Regions Research and Engineering Laboratory, Hanover, N.H., U.S.A.

†U.S. Navy Electronics Laboratory, Physical Oceanography Section, San Diego 52, Calif., U.S.A. 


\section{Physical setting}

When undertaking a study of the lateral variation of the salinity of sea-ice it is necessary to select an area of ice with a known history. The field measurements reported here were made in North Star Bay, Thule, northwestern Greenland (Fig. 1). When the scientific party arrived at Thule on October 12, 1956, the bay already had begun to freeze. During calm periods thin layers of sheet-ice would form in sheltered areas such as North Star Bay. These layers would usually be broken into pancakes and blown out to sea during the next period of offshore wind. By October 22 a large amount of drift-ice was present in the bay west of DeLong Pier. On October 26 a strong onshore wind developed, blowing the pancakes west of the pier back into the general area of the pier. Among this heterogeneous mixture of pancakes of different ages were a number of small bergy bits.

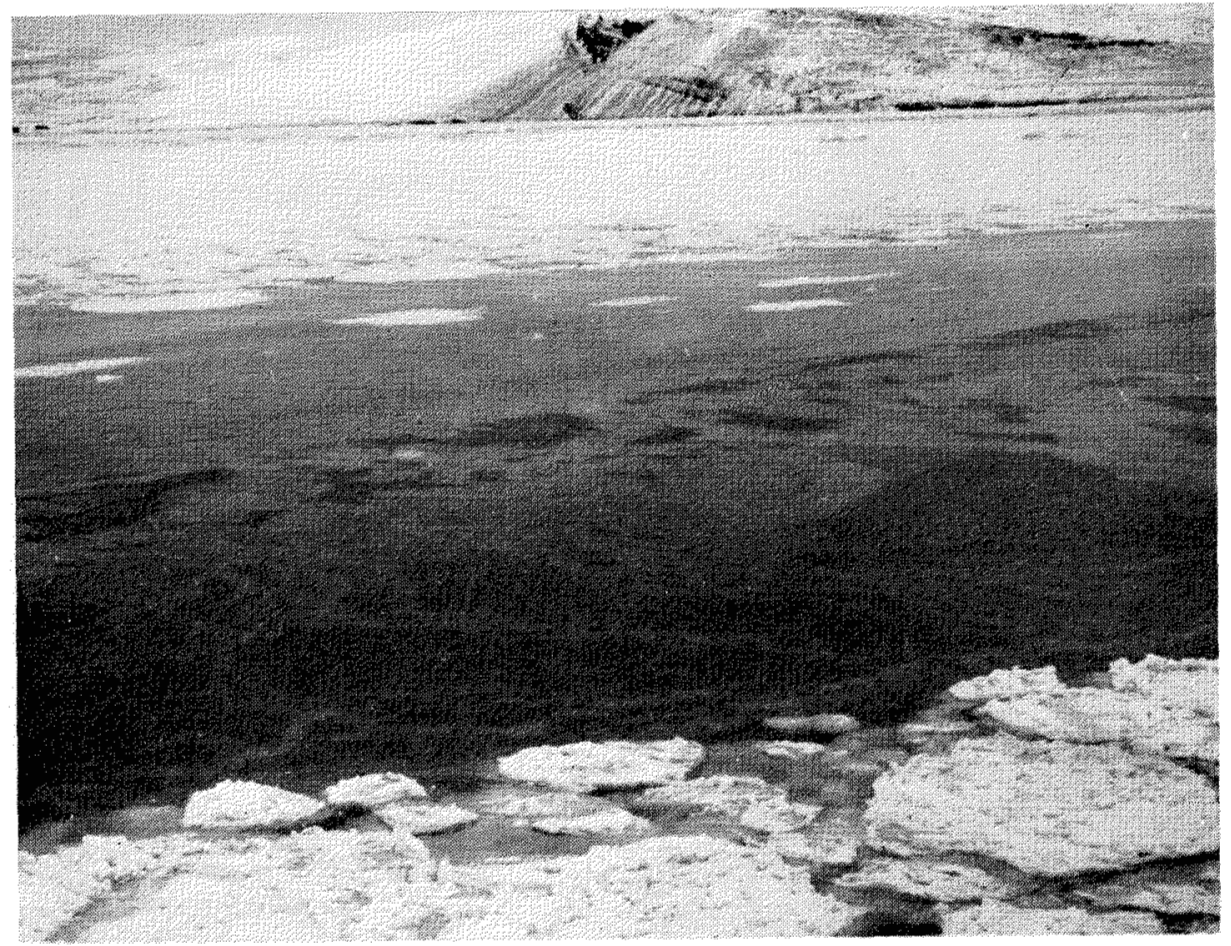

Fig. 2. The lead north of DeLong Pier after it had frozen over with a thin layer (ca. 5 $\mathrm{cm}$.) of dark sea-ice of high salinity.

When the authors visited the pier at 2300 hours in an attempt to secure their field equipment, the wind, which had been blowing from the west, had shifted to the south. This wind shift resulted in the opening of a 50-m.wide lead in the still unconsolidated pancakes north of the pier. The following morning (October 27) the ice-sheet had frozen solidly and the former 

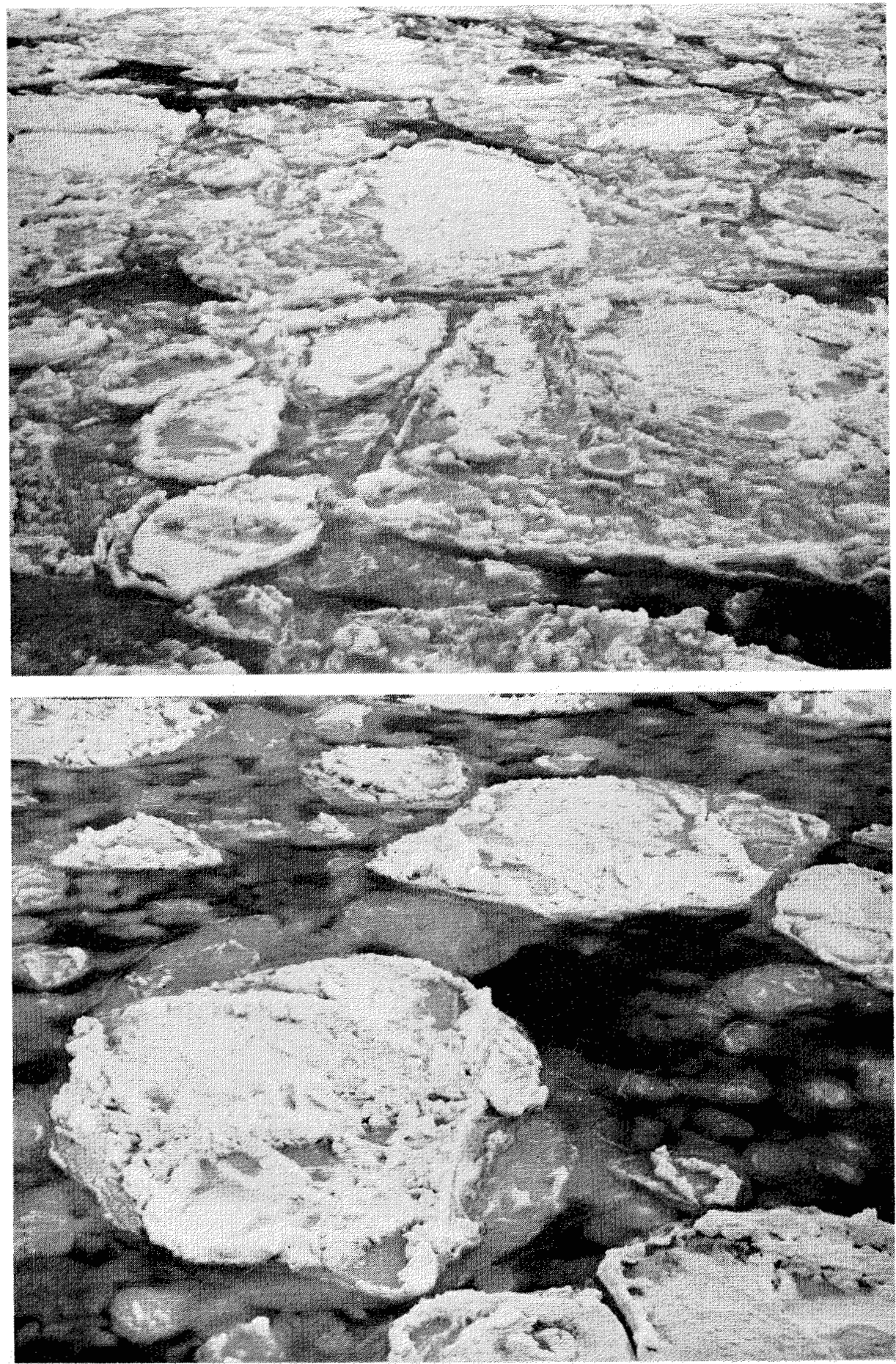

Fig. 3. Representative views of the heterogeneous pancake-ice north of DeLong Pier. The dark areas are composed of thinner sheet-ice. The size of the larger pancakes varies between 1 and 3 metres. 
lead was covered with a skim of sheet-ice that apparently formed after the wind had subsided (Fig. 2). The descriptive term, sheet-ice, is used in this paper as defined by Wilson, Zumberge, and Marshall (1954): “. . . an icecover which presents a smooth unbroken surface on which there are no highly evident horizontal changes in the structure of the ice layer".

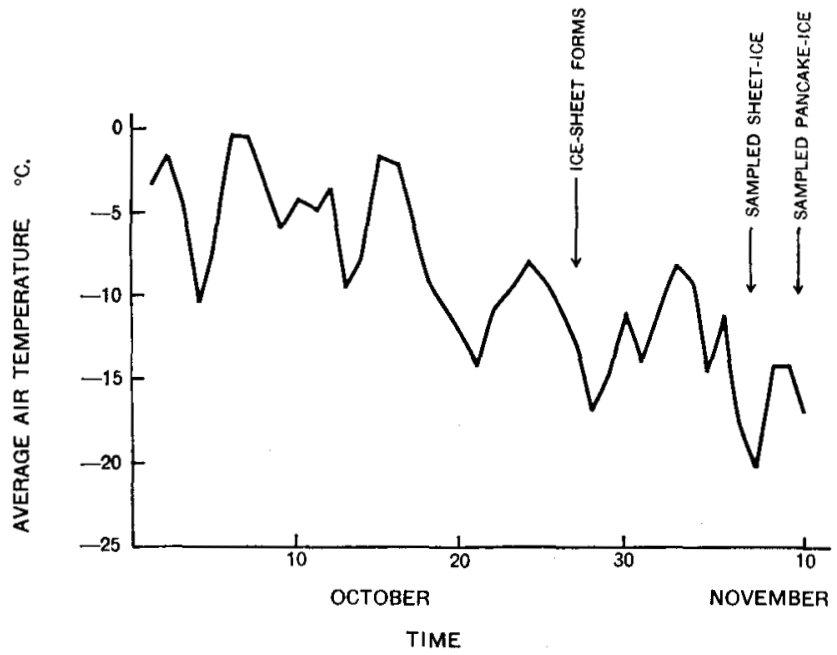

Fig. 4. Mean daily air temperatures from October 1 to November 10, 1956, at Thule, Greenland.

The same afternoon an attempt was made to walk on the heterogeneous ice-sheet south of the pier. The old pancakes were strong enough to support a man's weight, but in the areas between pancakes difficulty was experienced with breaking through the thin sheet-ice. On October 29 testing equipment

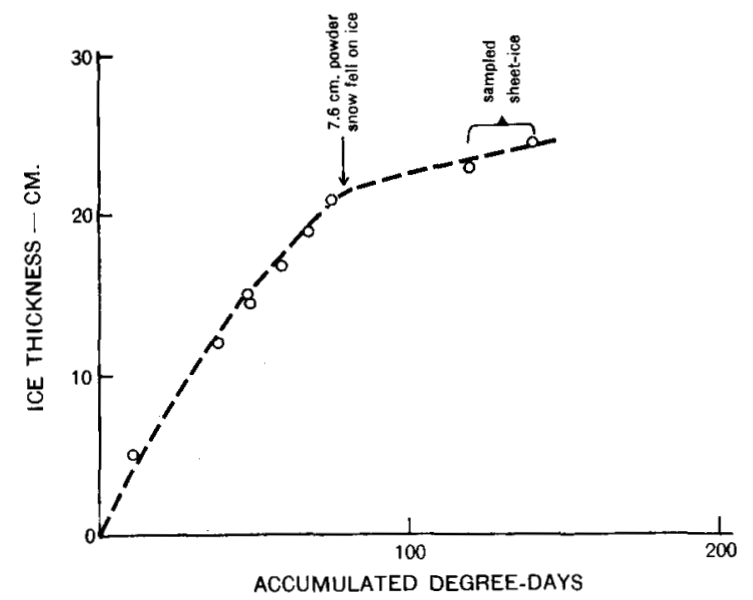

Fig. 5. Ice thickness in the test area as a function of the number of accumulated degree-days.

was moved on the ice-sheet north of the pier. At this time the ice in the former lead was $12 \mathrm{~cm}$. thick and that in the surrounding areas of heterogeneous pancake-ice was on the average $18 \mathrm{~cm}$. thick. Fig. 3 shows typical 
views of pancake-ice taken at this time. The dark areas in the figure are sheet-ice that had cemented the pancakes together to make what Wilson, Zumberge, and Marshall have termed a floe- or pan-agglomerate. For brevity this ice will here be referred to as pancake-ice.

Fig. 6. Typical salinity profiles from sheet sea-ice.

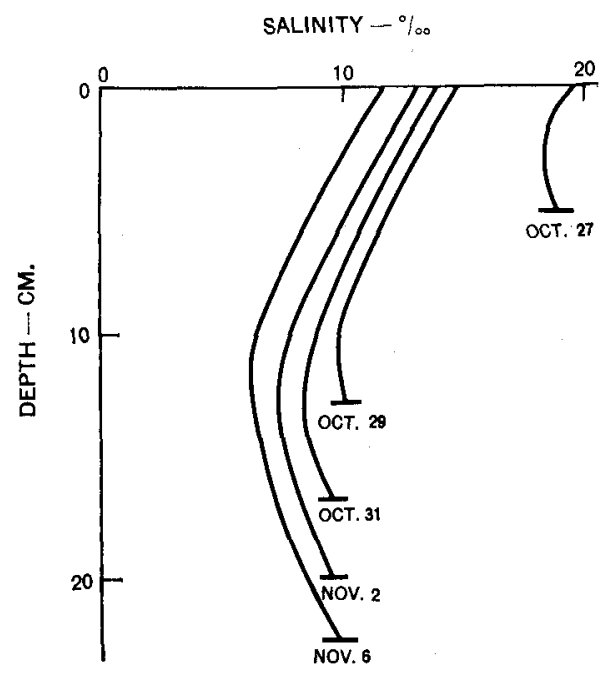

A graph of the daily average air temperatures recorded at Thule from October 1 to November 10, 1956 is presented in Fig. 4. Fig. 5 shows the sheet-ice thickness plotted against the sum of the accumulated degree-days

Fig. 7. Decrease in average salinity of sheet sea-ice with time.

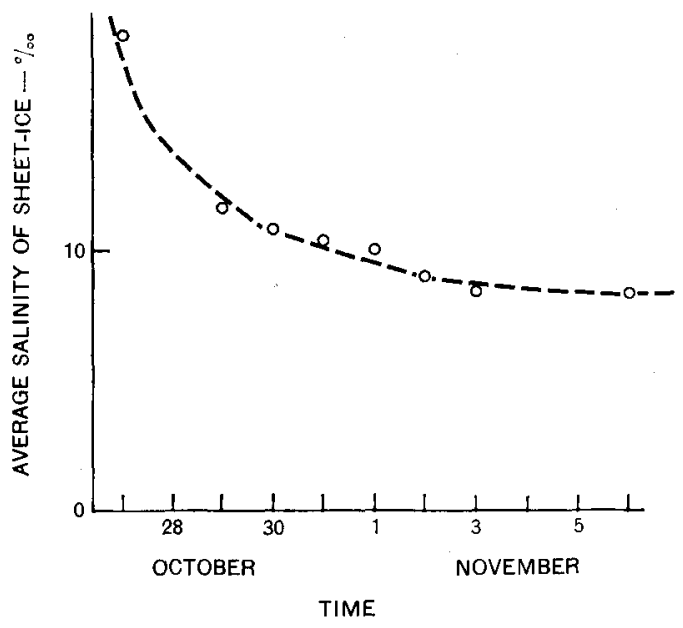

in relation to the freezing point of sea-water for the period between formation of the sheet-ice (October 27) and the time of testing (November 6). Fig. 6 shows a series of salinity profiles for the sheet-ice at different dates during this period. Fig. 7 shows the decrease in the average salinity of the sheet-ice with time. It is interesting to note the resemblance between Fig. 7 
and a similar graph based on data collected the previous winter at Hopedale, Labrador (Weeks and Lee 1958, Fig. 19, p. 151). It is hoped that the information presented in the figures will provide an accurate characterization of the history of the sheet-ice in the test area previous to the time of sampling. This will then facilitate a quantitative comparison between the salinity data presented in this paper and future studies of the salinity distributions in ice samples of different histories.

\section{Sampling procedures}

On November 6 the sheet-ice in the refrozen lead north of the pier was on the average $22.9 \mathrm{~cm}$. thick. On this sheet a series of nested rectangular grids were laid out in a manner schematically shown in Fig. 8. Before the grid systems were marked $7.6 \mathrm{~cm}$. of powder snow had fallen on the ice.

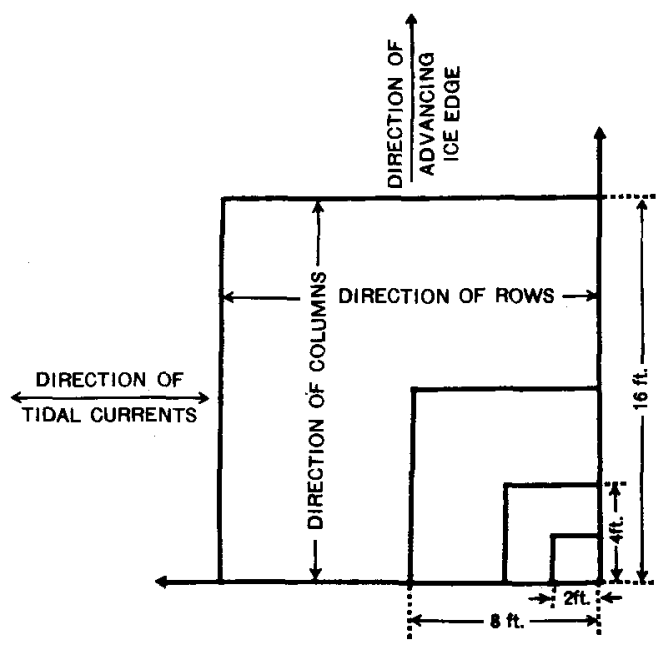

Fig. 8. Schematic diagram of the orientation of the salinity sampling grids in North Star Bay.

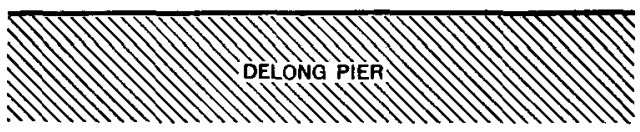

The snow effectively masked the detailed structures of the surface shown in Figs. 2 and 3. However, before the snow fell the general areas of sheetand pancake-ice were marked by wands frozen into the ice. The sides of the grids (L) were $2,4,8,16,32,64$, and 128 feet in length $(0.61,1.22,2.44$, 4.88, 9.75, 19.51, and 39.01 metres, respectively). Each grid was composed of 25 vertical $7.6-\mathrm{cm}$.-diameter cores whose centres were spaced L/4 units apart. In the 2-foot grid, only $7.6 \mathrm{~cm}$. separated adjacent cores (essentially the complete block was sampled). The grid system was oriented on the ice-sheet so that the rows were parallel to the direction of motion of the tidal currents and the columns would be perpendicular to the advancing edge of the ice when the lead froze. 
The sampling for the sheet-ice grid was started at 1100 on November 6 and by 2100 the $2-, 4-, 8-$, and 16 -foot grids were completed. The $32-, 64-$, and 128-foot grids were completed the following morning. Ideally all samples should be removed from the ice at the same time. However, since the initial rapid decrease in the average salinity of the sheet-ice with time had essentially ceased by the time of sampling (Fig. 7), any error introduced into the data by non-simultaneous sampling was considered to be small. The validity of this assumption will be discussed in detail below.

Care was taken to remove the cores quickly from the ice to prevent flooding of the core by sea-water. The cores were then immediately removed from the corer, placed in a mitre box and cut into three $7.6-\mathrm{cm}$. segments, measured from the upper ice surface. As a result of the rapid handling and the low air temperatures during the sampling period (about $-18^{\circ} \mathrm{C}$.) no difficulty was experienced with brine drainage from the cores.

The ice segments were then placed in tightly sealed glass containers and set in a heated shed. When the samples had melted and the temperature of the resulting solution had reached approximately $15^{\circ} \mathrm{C}$. the salinity of the sample was determined with a hydrometer. The same hydrometer was used to measure all samples so that, even if the hydrometer was miscalibrated, relative salinity values would be valid. The hydrometer float was graduated in $0.2 \%$ and values of $0.1 \%$ could easily be interpolated. Admittedly, if these samples had been titrated an accuracy of $0.02 \%$ could have been obtained. Titration was not used for the following reasons:

(a) One of the authors had previously experienced considerable difficulty as the result of the thermal instability of the $\mathrm{AgNO}_{3}$ solutions and the breakage of glassware resulting from the freezing of solutions (Lee 1956).

(b) Shipment of specimens back to an adequate laboratory prolongs storage of the specimens and increases the possibility of a change in the salinity as a result of evaporation from improperly sealed containers (Metcalf 1952).

(c) Evaluation of data collected during previous field seasons at Hopedale, Labrador indicated that the standard deviation of salinities from closely spaced samples taken at the same level in an apparently homogeneous icesheet was always greater than $0.3 \%$ and usually greater than $0.6 \%$ (Lee 1956). Therefore, it was considered that the accuracy of $0.1 \%$ obtained by hydrometer would be sufficient for the present study.

Sampling of the pancake-ice was started at 0900 on November 9 and completed by the evening of the same day. The general sampling procedure was similar to that used with the sheet-ice except that it was unnecessary to take complete vertical cores from the ice-sheet because the pancake-ice was appreciably thicker than $22.9 \mathrm{~cm}$. at the time of sampling. Instead, the ice was cored to a depth slightly greater than $22.9 \mathrm{~cm}$., the corer removed and the core broken free with an ice chisel. This sampling method removed the possibility of altering the salinity of the core by flooding. Two of the 121 cores were accidentally flooded by coring completely through the icesheet. The resulting salinity values did not, however, appear abnormally higher than those of unflooded cores. Each core was then cut into three 
7.6-cm. segments, measuring from the upper surface of the core. In the discussion of the distribution of salinity in both sheet- and pancake-ice these segments are referred to as upper, middle, and lower layer samples.

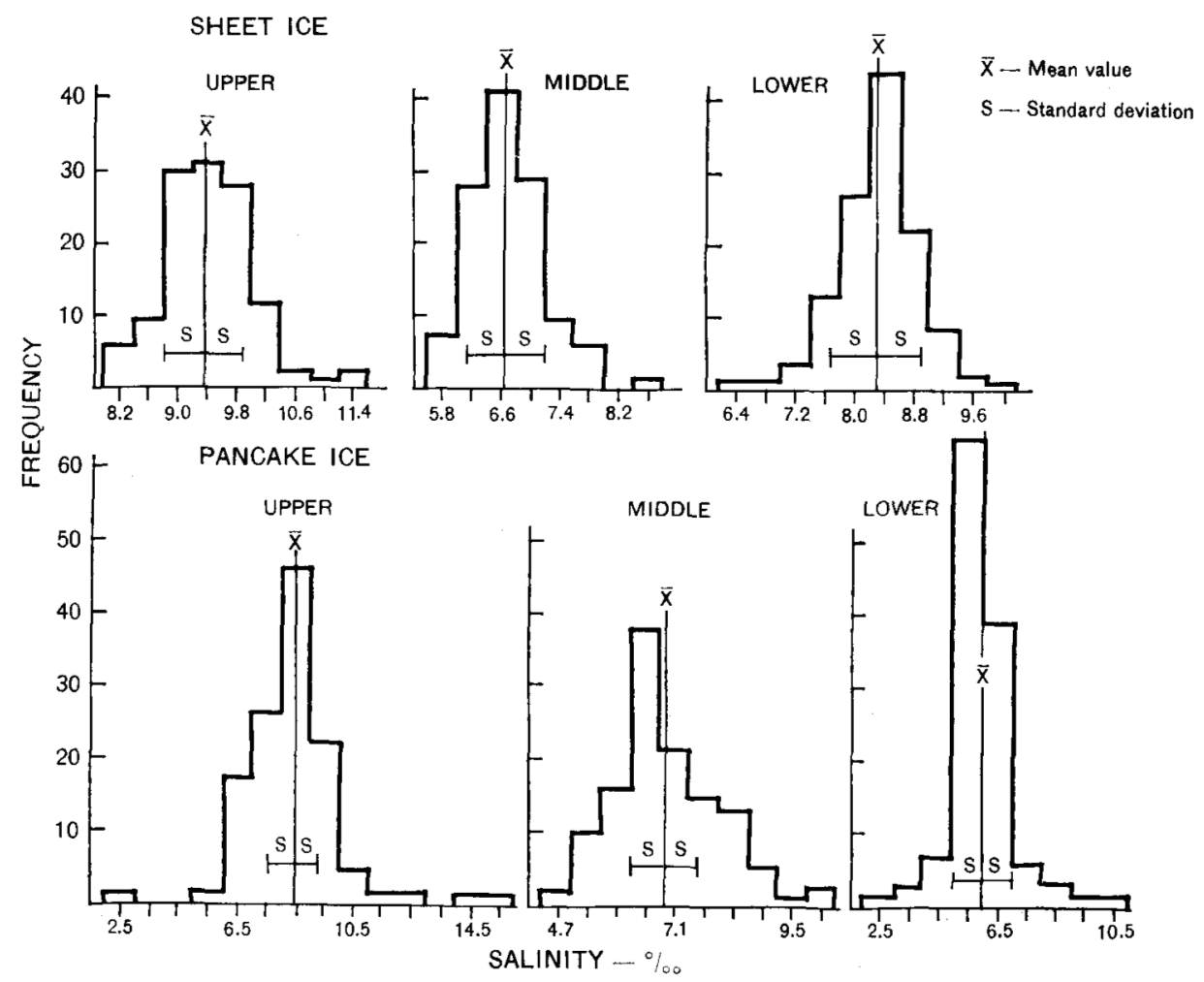

Fig. 9. The distribution of salinity values in the upper, middle, and lower layers of sheet and pancake sea-ice.

\section{Data analysis}

Fig. 9 shows frequency histograms of the salinity distributions from the upper, middle, and lower layers of sheet- and pancake-ice. The moment measures were used to find summary statistics that characterize these frequency distributions (Goulden 1952, p. 34-5). The calculated $\sqrt{\beta_{1}}$ statistics were tested for normality by comparing them with the theoretical ones expected on the basis of normality. The range in $\sqrt{\beta_{1}}$ due solely to random sampling is tabulated in Pearson and Hartley (1954). The results of this comparison are summarized in Table 1. Because the number of samples is small $(\mathrm{n}=121)$ it is impossible to compare $\beta_{2}$ with values that might have been drawn from a normal population. Even so it is possible to distinguish obvious cases of non-normality. 
All salinity distributions except those from the lower layer of sheetice show a positive skewness greater than would be expected in a random sample from a normal population. The salinity distribution from the lower layer of sheet-ice is negatively skewed although not significantly. The salinity distributions from all layers of both sheet- and pancake-ice show varying degrees of positive peakedness, i.e., a tendency to cluster around the mean. All but the middle layer of pancake-ice deviate significantly from normality on at least the 5-per-cent level of significance.

Table 1. Summary statistics of the salinity frequency distribution.

\begin{tabular}{|c|c|c|c|c|c|}
\hline & & $\overline{\mathrm{X}}$ & Variance & $\sqrt{\bar{\beta}_{1}}$ & $\beta_{\mathbf{2}}$ \\
\hline $\begin{array}{l}\text { Sheet-ice } \\
\text { Pancake-Ice }\end{array}$ & $\begin{array}{l}\text { Upper layer } \\
\text { Middle layer } \\
\text { Lower layer } \\
\text { Upper layer } \\
\text { Middle layer } \\
\text { Lower layer }\end{array}$ & $\begin{array}{l}9.337 \\
6.631 \\
8.302 \\
8.393 \\
6.871 \\
5.896\end{array}$ & $\begin{array}{l}0.299 \\
0.259 \\
0.389 \\
0.797 \\
0.591 \\
1.131\end{array}$ & $\begin{array}{l}+0.463^{*} \\
+0.744 \dagger \\
-0.217 \mathrm{NS} \\
+1.094 \dagger \\
+0.622 \dagger \\
+1.092 \dagger\end{array}$ & $\begin{array}{l}+3.907 \\
+4.001 \\
+4.281 \\
+10.153 \\
+3.216 \\
+8.460\end{array}$ \\
\hline
\end{tabular}

* Significant at the 5 per cent level

+ Significant at the 1 per cent level NS Not significant

The salinities from the lower layer of sheet-ice are the only ones determined on specimens from immediately above the ice-water interface. It is therefore reasonable to interpret the absence of a positive skew in these samples as resulting from brine drainage during sampling. It is known that the chlorinity of sea-ice samples decreases rapidly after they are removed from an ice-sheet (Kusunoki 1955). This is particularly true in the lower layer of the ice-sheet where the near-freezing ice temperatures result in large brine volumes for a given salinity. This would cause many of the brine pockets to be interconnected, resulting in rapid brine drainage. At higher layers in the ice-sheet the brine volume is reduced as a result of the lower ice temperature, brine pockets are no longer interconnected, and brine drainage is much slower. If a few cores remained on the sampling table too long, a slight negative skew might be produced in the salinity values from the lower sampling layer.

The large variance and positive skew observed in the pancake-ice is the result of the mixing of ice of two different histories. Since the salinity of a newly formed ice-sheet decreases rapidly with time (as shown by Fig. 7; Weeks and Lee 1958, Fig. 19), a significant difference is to be expected between the salinities of the older pancake floes and the newly formed sheet-ice that combine to make up the pancake-ice. Sheet-ice is found between the pancakes and forms a small percentage of the total pancake-ice (Fig. 3). This results in a large number of low salinities and a few high salinities producing positively skewed distributions. If this interpretation is correct, it should be noted that a bimodal distribution could be produced 
by a composite ice-sheet containing approximately 50 per cent old pancakes and 50 per cent sheet-ice, whereas a strongly negatively skewed distribution could result from a composite ice-sheet composed mainly of sheet-ice with a few old pancakes.

Since Cochran (1947) has shown that, in practice, analysis of variance methods are valid unless the sample distribution is extremely skewed, it was decided to use a single-factor basic form with single-cell entries (Dixon and Massey 1951) to test the variability between the nested sampling grids and between different layers of each grid. The null hypothesis being tested supposes that there is no difference in the means of the different grids or layers at the 0.05 level of significance (that there is no greater difference among the grids or layers than among sets of similar samples drawn from a homogeneous population). To test this, the between-grid variance is compared with the within-grid variance. If the ratio of these variances does not exceed a significance level of 0.05 , the hypothesis is accepted.

Table 2. Between-layer analysis of variance (2-foot grids).

\begin{tabular}{|c|c|c|c|c|c|}
\hline & & Sum of squares & $d . f$. & Variance & $F$ ratio \\
\hline \multirow[t]{2}{*}{ Sheet-ice } & $\begin{array}{l}\text { means } \\
\text { within }\end{array}$ & $\begin{array}{l}98.9 \\
14.5\end{array}$ & $\begin{array}{r}2 \\
72\end{array}$ & $\begin{array}{l}49.4 \\
0.202\end{array}$ & $\begin{array}{l}F=244.9^{*} \\
F_{0.99}(2,72)=4.91\end{array}$ \\
\hline & total & 113.4 & 74 & & \\
\hline \multirow[t]{2}{*}{ Pancake-ice } & $\begin{array}{l}\text { means } \\
\text { within }\end{array}$ & $\begin{array}{l}82.5 \\
10.0\end{array}$ & $\begin{array}{r}2 \\
72\end{array}$ & $\begin{array}{c}41.2 \\
0.139\end{array}$ & $F=296.9^{*}$ \\
\hline & total & 92.5 & 74 & & \\
\hline
\end{tabular}

*Significant at the 1 per cent level

The results of the between-layers analysis (Table 2) clearly indicate that there is a highly significant vertical variation in the salinity of young sea-ice. This variation has been known since the work of Malmgren (1927) and is the combined result of the general decrease in the salinity of the ice with decreasing growth rate and the transfer processes that produce brine migration after the salt has been incorporated in the ice-sheet.

The analysis presented in Table 3 indicates that the between-grid variance is significant at the 0.01 level for all layers of sheet-ice and not significant for all layers of pancake-ice. It is believed that the between-grid variance observed on sheet sea-ice results from a small but measurable decrease in the salinity of the ice-sheet during the period of sampling. Because of the low standard deviation in the salinity values from a given layer in the sheet-ice, these small differences can be distinguished by analysis of variance. Therefore, the assumption of instantaneous sampling is invalid. This means that the samples in the larger grids can no longer be considered as a homogeneous population representing the lateral salinity distribution in the sheet-ice at a given moment. Therefore, the data were distributed 
Table 3. Between-grids analysis of variance.

\begin{tabular}{|c|c|c|c|c|c|}
\hline & & Sum of squares & $d . f$. & Variance & $F$ ratio \\
\hline \multirow[t]{2}{*}{$\begin{array}{l}\text { Sheet-ice } \\
\text { Upper grids }\end{array}$} & $\begin{array}{l}\text { means } \\
\text { within }\end{array}$ & $\begin{array}{l}10.34 \\
69.73\end{array}$ & $\begin{array}{r}6 \\
168\end{array}$ & $\begin{array}{l}1.72 \\
0.42\end{array}$ & $\begin{array}{l}F=4.10^{*} \\
F_{0.99}(6,168)=2.92\end{array}$ \\
\hline & total & 80.07 & 174 & & \\
\hline \multirow[t]{2}{*}{ Middle grids } & $\begin{array}{l}\text { means } \\
\text { within }\end{array}$ & $\begin{array}{r}4.21 \\
39.92\end{array}$ & $\begin{array}{r}6 \\
168\end{array}$ & $\begin{array}{l}0.70 \\
0.24\end{array}$ & $\mathrm{~F}=2.92^{*}$ \\
\hline & total & 44.13 & 174 & & \\
\hline \multirow[t]{2}{*}{ Lower grids } & $\begin{array}{l}\text { means } \\
\text { within }\end{array}$ & $\begin{array}{l}13.77 \\
32.93\end{array}$ & $\begin{array}{r}6 \\
168\end{array}$ & $\begin{array}{l}2.30 \\
0.20\end{array}$ & $\mathrm{~F}=11.50^{*}$ \\
\hline & total & 46.70 & 174 & & \\
\hline \multirow[t]{2}{*}{$\begin{array}{l}\text { Pancake-ice } \\
\text { Upper grids }\end{array}$} & $\begin{array}{l}\text { means } \\
\text { within }\end{array}$ & $\begin{array}{r}15.86 \\
331.17\end{array}$ & $\begin{array}{r}6 \\
168\end{array}$ & $\begin{array}{l}2.64 \\
1.97\end{array}$ & $\begin{array}{c}F=1.34 \mathrm{NS} \\
\mathrm{F}_{0.95}(6,168)=2.16\end{array}$ \\
\hline & total & 347.03 & 174 & & \\
\hline \multirow[t]{2}{*}{ Middle grids } & $\begin{array}{l}\text { means } \\
\text { within }\end{array}$ & $\begin{array}{r}3.48 \\
164.86\end{array}$ & $\begin{array}{r}6 \\
168\end{array}$ & $\begin{array}{l}0.58 \\
0.98\end{array}$ & $\mathrm{~F}=0.59 \mathrm{NS}$ \\
\hline & total & 168.34 & 174 & & \\
\hline \multirow[t]{2}{*}{ Lower grids } & $\begin{array}{l}\text { means } \\
\text { within }\end{array}$ & $\begin{array}{r}5.00 \\
211.57\end{array}$ & $\begin{array}{r}6 \\
168\end{array}$ & $\begin{array}{l}0.83 \\
1.26\end{array}$ & $F=0.66 \mathrm{NS}$ \\
\hline & total & 216.57 & 174 & & \\
\hline
\end{tabular}

*Significant at the 1 per cent level NS Not significant

into groups sampled at essentially the same time. Fig. 10 shows the average salinity of these time groups plotted against increasing age of the ice-sheet in arbitrary time units that are of the order of hours. A systematic decrease in salinity is evident in all cases.

In the pancake-ice there is no significant between-grid variance and this suggests that the salinities could have been selected from a single homogeneous population. The absence of significant between-grid variance is probably due in part to the large within-grid variance that resulted from the grouping of ice samples of different histories to produce the pancake ice-sheet. Moreover, the change in the salinity of the older pancakes during the period of sampling would be much less than in the younger sheet-ice because the average salinity of an ice-sheet decreases as an exponential function of time. Fig. 10 shows that the average salinities of the time groups of pancake-ice do not show a systematic decrease with increasing age during the sampling period.

To study the possibility of a systematic increase in sample variance with an increase in the distance between samples, the variance around the mean for each time group was computed. Least squares analyses were then 
made of plots of log (variance) against log (area of sampling grid). The correlation coefficients and t-ratios for the linear regression lines are presented in Table 4. Only in the upper layer of the pancake-ice is there a significant increase ( $t$ greater than 3.0) in the variance with an increase in the area of the sample pattern. Such an increase is readily understandable: as the size of the sample grid increases the samples are collected from pancakes of widely varying histories.

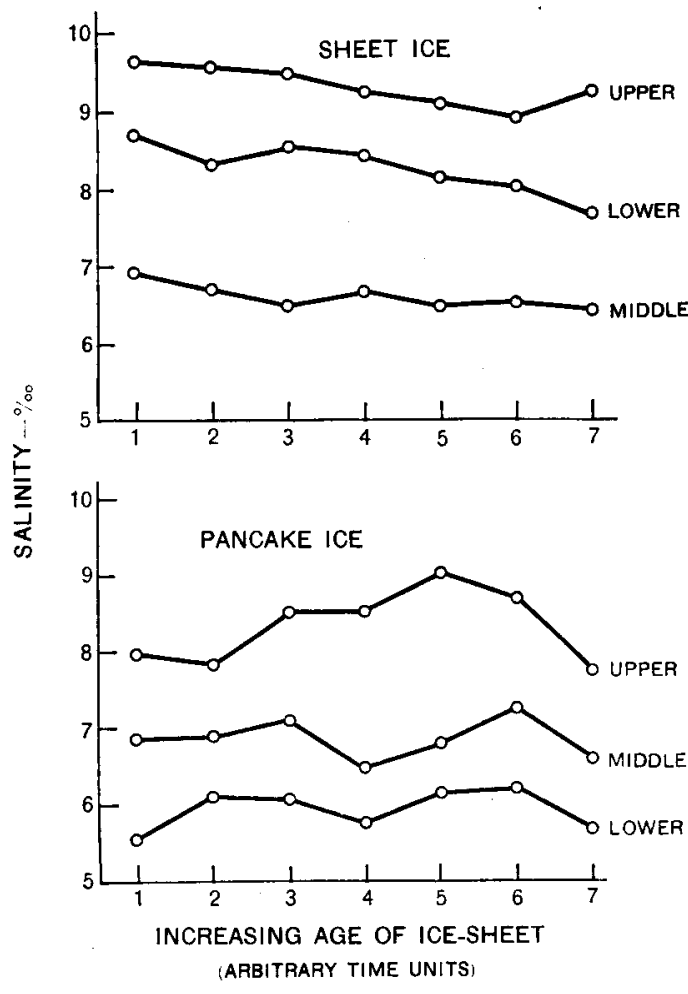

Fig. 10. The average salinities of groups of cores collected from the sheet- and pancake-ice vs. the increasing age of the ice-sheet in arbitrary time units.

To determine the possible presence of small domains of different salinities in a given layer in the ice-sheet, the correlation coefficient, $\mathbf{r}$, was computed for groups of salinity samples as a function of the sample spacing between the data pairs. The correlation coefficients for the upper layers of sheet- and pancake-ice are plotted against sample spacings in Fig. 11. The number of data pairs, $n$, used in computing each coefficient is 30 or more in all but the 96- and 128-foot sample spacings where $\mathrm{n}$ is 20 and 10 respectively. In the sheet-ice the correlation coefficient changes from a value of +1 at the sample spacing of 0 to values of less than \pm 0.3 at larger sample spacings. With the exception, of course, of the zero spacing value, none of these coefficients indicate a significant degree of correlation.

The pancake-ice correlation coefficients show trends similar to those of the sheet-ice. Only in one case, the 22.6 -foot sample spacing, is there a 
Table 4. Statistical data on the linear regression equations from plots of log (variance) against log (sample grid area).

\begin{tabular}{cccccc}
\hline & \multicolumn{2}{c}{ Sheet-ice } & & \multicolumn{2}{c}{ Pancake-ice } \\
\cline { 2 - 3 } $\begin{array}{c}\text { Sample } \\
\text { layer }\end{array}$ & $\begin{array}{c}\text { Correlation } \\
\text { coefficient }\end{array}$ & $\begin{array}{c}t \\
\text { ratio }\end{array}$ & & $\begin{array}{c}\text { Correlation } \\
\text { coefficient }\end{array}$ & $\begin{array}{c}t \\
\text { ratio }\end{array}$ \\
\hline upper & 0.4508 & 1.1292 & 0.8469 & 3.5614 \\
middle & 0.1904 & 0.4337 & & 0.1837 & 0.4179 \\
lower & 0.0427 & 0.0955 & & 0.5238 & 1.3750
\end{tabular}

marginal correlation at the 0.05 level of significance. This correlation is probably caused by the sampling grid being partly on an old pancake and partly on younger sheet-ice. This would produce two homogeneous salinity domains separated by a definite boundary within the sampling grid and cause an increase in the correlation coefficient. There also appears to be a slight increase in the absolute magnitude of the correlation coefficient, $|\mathbf{r}|$, at the smaller sample spacings.

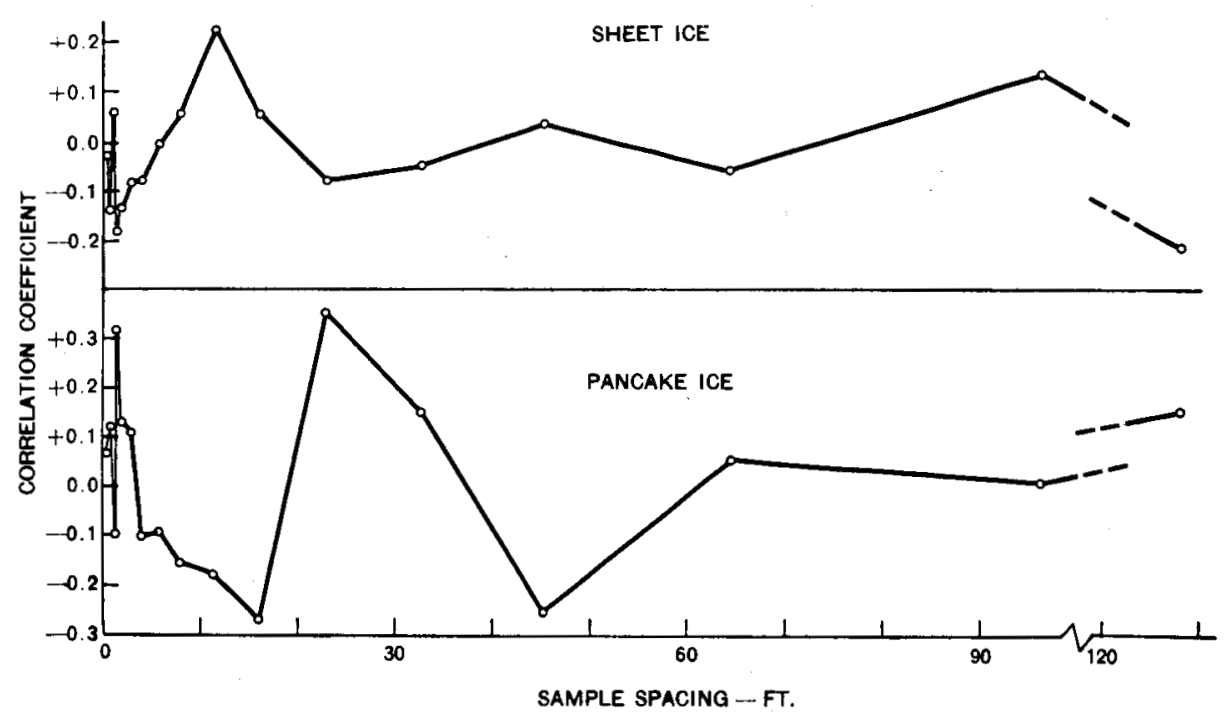

Fig. 11. Correlation coefficient vs. sample spacing in feet for the upper layers of sheetand pancake-ice.

Since the distribution of the correlation coefficients may possibly be decidedly skewed, the $\mathbf{r}$ values were transformed to the statistic $Z$ (Fisher 1954), which is approximately normally distributed, $Z=\frac{1}{2} \ln \left(\frac{1+r}{1-r}\right)$. The observed $\mathrm{Z}$ statistics can now be tested to determine the possibility that they were drawn from a random population by computing a weighted 
arithmetical mean:

$$
\bar{Z}=\frac{\left(\mathrm{n}_{1}-3\right) Z_{1}+\left(\mathrm{n}_{2}-3\right) Z_{2}+\ldots}{\left(\mathrm{n}_{1}-3\right)+\left(\mathrm{n}_{2}-3\right)+\ldots}
$$

and the standard error of $\mathbf{Z}$ :

$$
\mathrm{S}_{\mathrm{Z}}=\frac{1}{\sqrt{\left(\mathrm{n}_{1}-3\right)+\left(\mathrm{n}_{2}-3\right)+\ldots}} .
$$

For sheet- and pancake-ice the weighted means were -0.0234 and +0.0003 , respectively. The standard error of $Z$ was 0.0442 . If the variation in salinity is random, the mathematical expectation of $Z$ is zero. The $t$ ratios $Z / S_{z}$ were then tested and in both sheet- and pancake-ice there is no reason to doubt that the observed $Z$ values were drawn from a population with a mean of zero. It can be concluded, therefore, that the effects causing the variation in salinity are random.

As the result of the significant between-grid variance in sheet-ice, it is not possible to give an unbiased estimate of the population mean over the large grid at a given time. In the 2-foot grid, which was sampled during a short period of time, the average values and standard deviations are as follows: upper layer, $9.7 \pm 0.6 \%$; middle layer, $6.9 \pm 0.3 \%$; and lower layer, $8.7 \pm 0.5 \%$. An unbiased estimate of the population mean in the pancakeice is simply the arithmetic mean of the total number of samples. These averages and standard deviations are as follows: upper layer, $8.4 \pm 0.9 \%$; middle layer, $6.9 \pm 0.8 \%$; and lower layer, $5.9 \pm 1.1 \%$.

\section{Conclusions}

Usually, when studies are performed on the physical properties of seaice, the scientific party arrives in the field a week to several months after the date of freeze-up. The ice surface is then covered with a layer of snow and little, if any, evidence is visible as to whether the ice-sheet under study was originally pure sheet-ice or some variety of pancake-ice. Tests are performed on the ice-sheet and salinity measurements are taken to represent the salinity of the test specimen. As was shown in the correlation analysis, unless the salinity of the specific volume of sea-ice that is involved in the physical test can be measured, the correlation coefficient between the test salinity and the salinity of nearby cores is no larger than would be expected if the values had been selected from a completely random population. For pancake-ice, however, since there is a significant increase in the variance around the mean as the sample spacing is increased, the standard deviation of the sampled population will be minimized by collecting salinity samples for the upper layer of the ice-sheet close to the test area. In sheet-ice and in the lower layers of pancake-ice below the thickness of the initial pancakes, there is no increase in variance as the sampling spacing is increased, and collecting the salinity samples close to the test site does not cause either an increase in correlation or a decrease in the standard deviation of the population of the sampled area. 
Even in ring-tensile or other small-scale strength tests, although it is possible to obtain the bulk salinity of the complete test specimen, it is doubtful whether a significant increase in correlation would be achieved since the salinity of the $7.6-\mathrm{cm}$. segment of core in which the break occurs can no longer be considered as an individual in the salinity population under study (Krumbein 1960). The individual value in whose variation we are now interested is the effective salinity of the brine "layers" that separate the subplates of pure ice in a single crystal of sea-ice (Weeks 1958). Since the salinity of each sample used in the present study is the average of a large number of such subplatelet salinities, the actual standard deviation of the salinity population of interest would always be larger than the standard deviation as determined from the scatter in the salinities of the cored samples. Therefore, there appears to be no sampling design that will cause the salinity sample to be a better representative of the salinity of the specific volume of ice being tested than the standard deviation of the lateral variation of the salinity values in that part of the ice-sheet.

As the data presented in this paper show, the standard deviation of the salinity values from closely spaced cored samples in sheet-ice is always equal to or greater than $\pm 0.3 \%$. In pancake-ice the standard deviation is usually $\pm 1.0 \%$. Using the phase diagram for standard sea-ice as published by Assur (1958, p. 138), it can be seen that this uncertainty will produce a standard deviation of approximately \pm 4 to 6 per cent of the total brine volume in the sheet-ice and \pm 11 to 19 per cent of the total brine volume in pancake-ice. This then accounts for a considerable proportion of the scatter observed in studying the strength properties of sea-ice.

\section{Acknowledgements}

This paper is one of series of reports on field work performed during a sea-ice research project at Thule, Greenland in 1956-57 undertaken jointly by the Geophysics Research Directorate, Air Force Cambridge Research Center; the U.S. Navy Hydrographic Office; and the Snow, Ice, and Permafrost Research Establishment, U.S. Army Corps of Engineers. The field measurements on which this report is based were made while the authors were associated with AFCRC (W.F.W.) and NHO (O.S.L.). One of the authors (W.F.W.) should also like to acknowledge the sponsorship of an AFCRC subcontract through the Arctic Institute of North America and an USA - SIPRE contract. The numerical calculations in the paper were performed using the USA - SIPRE computer facilities. The authors should like to express their appreciation to Drs. A. Assur of CRREL, G. C. Curl of USNEL, and P. E. Potter of the Illinois Geological Survey, for critically reading and helping to clarify many points in the final manuscript. Thanks are also due to the late Clarence Janifer of NHO who assisted with field measurement.

This report has been reviewed and approved for publication by the Chief of Engineers, U.S. Army and the U.S. Navy Electronics Laboratory. 


\section{References}

Anderson, D. L. 1958. A model for determining sea ice properties. U.S. Natl. Acad. Sci. - NRC Pub. 598, pp. 148-52.

-1960. The physical constants of sea ice. Research 13:310-18.

Anderson, D. L., and W. F. Weeks. 1958. A theoretical analysis of sea ice strength. Trans. Am. Geophys. Union. 39:632-40.

Assur, A. 1958. Composition of sea ice and its tensile strength. U.S. Natl. Acad. Sci. NRC Pub. 598, pp. 106-38.

Butkovich, T. R. 1956. Strength studies of sea ice. USA SIPRE Res. Rept. 20, 15 pp. 1959. On the mechanical properties of sea ice, Thule, Greenland, 1957.

USA SIPRE Res. Rept. 54, 11 pp.

Cochran, W. G. 1947. Some consequences when the assumptions for the analysis of variance are not satisfied. Biometrics 3:22-38.

Dixon, W. J., and F. J. Massey. 1951. Introduction to statistical analysis. New York: McGraw-Hill, 361 pp.

Fisher, R. A. 1954. Statistical methods for research workers. New York: Hafner, 351 pp.

Goulden, C. H. 1952. Methods of statistical analysis. New York: Wiley and Sons, $467 \mathrm{pp}$.

Krumbein, W. C. 1960. The "geological population" as a framework for analyzing numerical data in geology. Liverpool and Manchester Geol. J. 2:341-68.

Kusunoki, K. 1955. On the method of sampling of sea ice. Proc. UNESCO Sympos. Phys. Oceanogr., Tokyo, 38-42.

Lee, O. S. 1956. Sea ice investigations in support of NEAC operations. US Navy Hydro. Off. Rept., mimeogr., 17 pp.

Malmgren, F. 1927. On the properties of sea ice. Norweg. North Polar Exped. Maud (1918-25), Sci. Results. Vol. I, No. 5, 67 pp.

Metcalf, W. G. 1952. Discussion following paper by Barnes, C. A. Sea Ice problems. U.S. Natl. Acad. Sci. - NRC Pub. 309, p. 98.

Pearson, E. S., and H. O. Hartley. 1954. Biometrika table for statisticians 1, Cambridge: University Press, $238 \mathrm{pp}$.

Petrov, I. G. 1955. Physical-mechanical properties and thickness of ice cover, in Somov, M. M. (ed.) Observational data of the scientific research drifting station of 1950-51. Leningrad, Izd. "Morskoi Transport".

Weeks, W. F. 1958. The structure of sea ice: a progress report. U.S. Natl. Acad. Sci. NRC Pub. 598, pp. 96-8.

Weeks, W. F., and D. L. Anderson. 1958. An experimental study of the strength of young sea ice. Trans. Am Geophys. Union 39:641-7.

Weeks, W. F., and O. S. Lee. 1958. Observations on the physical properties of sea-ice at Hopedale, Labrador. Arctic 11:134-55.

Wilson, J. T., J. H. Zumberge, and E. W. Marshall. 1954. A study of ice on an inland lake. USA SIPRE Res. Rept. 5, 78 pp. 